\title{
Discussion and Practice on the Specialized English Teaching for Students Majoring in Automation
}

\author{
Beibei Wei ${ }^{1, \text { a }}$, Kai Sun ${ }^{2, \mathrm{~b}}$ and Juan $\mathrm{Li}^{1, \mathrm{c}}$ \\ ${ }^{1}$ School of Foreign Languages, Shandong Normal University, Jinan 250014, China \\ ${ }^{2}$ Department of Automation, Qilu University of Technology, Jinan 250353, China \\ asdnubaby@126.com, 'sunkai79@qlu.edu.cn, 'Juanlisdnu@126.com
}

\begin{abstract}
The paper introduces the design, contents and methods of teaching of specialized English for students majoring in automation, which avoids the disadvantages of traditional teaching approaches and aims at improving students' abilities to acquire information and to communicate. Task-based teaching method and the notion of student-centeredness is taken, with various of activities organized in and after class. Assessment on students is based on the contents of teaching, with the purpose of developing students' reading comprehension, and fostering their abilities to consult references, to sort out materials, to make multimedia courseware and to express themselves clearly and relevantly to their major. The results shows that the reform is effective and can increase students' specialized English competence obviously.
\end{abstract}

Keywords-Specialized English; College students; Automation; Task-based teaching

\section{INTRODUCTION}

Automation is a comprehensive applied basic subject which evolves with the development of electronic technique, computer technology and automatic control theory, and contains major fields such as motion control, automatic detection and industrial process control [1]. It belongs to high and new technology industry, with a short updating cycle of knowledge, and thus is one of the most important subjects of scientific and technological development strategy, which meets the great talents demand in this professional field. In today's globalization, the cultivation of talents who hold solid professional skills, high English competence, and international perspective should be the top priority of university education in this major [2]. Specialized English for automation is a compulsory course for automation majors, the teaching goal of which is letting students be aware of the characteristics of this course, be familiar with and grasp the required vocabulary, and fostering their abilities to consult references, translate materials relating to automation, write scientific and technological papers and exchange information and ideas concerning this major.

Currently, traditional teaching model still prevails in English teaching for automation [3]. Teachers tend to give lectures on the interpretations of vocabulary and sentences rather than let students involved in class activities more. The contents of teaching are out of date (outmoded) and the atmosphere in class is tedious (monotonous) and unmotivating. Under these circumstances, students have very little interest in learning and just passively receive knowledge by simply translating original materials into Chinese without thinking independently or taking part in class activities [4]. If thing go on like this, they will be poor at reading comprehension, paper writing and oral expression.

To improve the teaching effects and raise students' interest in learning, teaching contents in this study have been redesigned with an orientation toward developing students' ability to acquire information and communicate with each other

Meanwhile, teaching methods have been improved by implementing (carrying out) task-based activities focusing on actual projects. Cultivating students' abilities to consult references, sort out documents(materials), make multimedia courseware and express themselves should be the teaching purpose aside from fostering their basic reading and understanding ability. Assessment on students has been improved by focusing on students' overall (comprehensive) abilities according to teaching contents, and therefore reflecting teaching process.

\section{REFORMS OF THE TEACHING ACTIVITIES}

\section{A. Design of teaching contents}

The teaching contents for majors in automation mainly include two parts, namely, the appointed contents in prescribed textbooks and the customized contents for students. Teaching materials should cover a knowledge area ranging from automation and detective technology, to process control and robot technology, and an overall vocabulary relevant to the subject [5-6]. Textbooks should contain basic and important vocabulary about automation concepts, principles, techniques, and application. Since students have already grasped relevant basic knowledge about automation theories, techniques and application, they are required to preview the texts, take quizzes in class and do some A\&Q activities after class [7].

Nevertheless, this major belongs to high and new technology industry, and the cycle of knowledge is relatively short, the result of which is that textbooks tend to be timesensitive. Therefore, specialized English teaching resources and materials acquired from international conferences, journal papers and authoritative websites are needed, which are required to meet the demand of frontier major development, and the contents of which should be concise and succinct with 
moderate difficulty [8]. These teaching resources and materials should also aim at fostering students' competence in reading and writing professional publications. For the above reasons and purposes, the study discusses a teaching model based on customized contents for students. The specific contents and procedures are as follows.

- Firstly, the teacher introduces major orientation and research highlights in this major field, stimulates students' interest and provides certain key words.

- Secondly, students make use of the rich academic resources database such as Medalink and Springer provided by the university, retrieving and downloading papers and resources they are interested in based on the key words given by the teacher.

- Thirdly, students spend some time reading the retrieved papers, materials or resources, comprehending them and choosing those with moderate length and difficulty to translate, and then making PPT files as subjective reports before issuing them on the website platform.

- Finally, the teacher does the screening of the online contents issued by students, selects those representative reports which are made exquisitely and accordantly with the teaching requirements, and contain original and novel ideas. Subsequently the teacher asks students to report their work orally in class and then discuss on what has been presented to them.

\section{B. Organization of in-class and after-class activities}

Based on the teaching contents mentioned above, activities such as in-class quizzes, after-class Q\&A, PPT design, oral reports and group discussion should be carried out. To be more specific,

- Firstly, in-class quizzes are organized constantly to consolidate students' grasp of teaching contents, the marks of which will be part of their final grades at the end of each semester, for the purpose of raising their awareness of the importance of quizzes.

- The teacher answers students' questions in their learning process in a fixed classroom every four weeks and communicates with them about expressing in English, specialized knowledge, and retrieving resources

- Students make PPT files in English based on the frontier professional papers and materials they have already searched, meeting the requirement to be explicit in contents, clear in thoughts, moderate in length, and normative in typesetting.

- Students present subjective reports within 5 minutes each time they are given specific instructions and requirements, which should be a very important part in testing their learning outcomes.

- The teacher organizes group discussion among students according to teaching contents in order to improve students' expressive ability and consolidate what they have learned.
Figure 1 shows a typical PPT made by a student majoring in Automation. In the project, the students gave an introduction of automatic water control system. The content aims to teach the students that automation system is a design for automatic monitoring and control of the industrial process to obtain the ideal results without any manual interventions. The information query and PPT production are finished by the students independently.

\section{Automatic water level controller}

The presentation for automation making by chenx

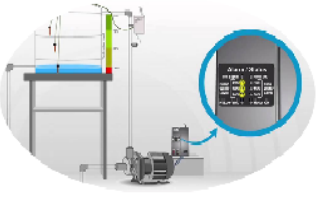

\section{Water Level controller feature}

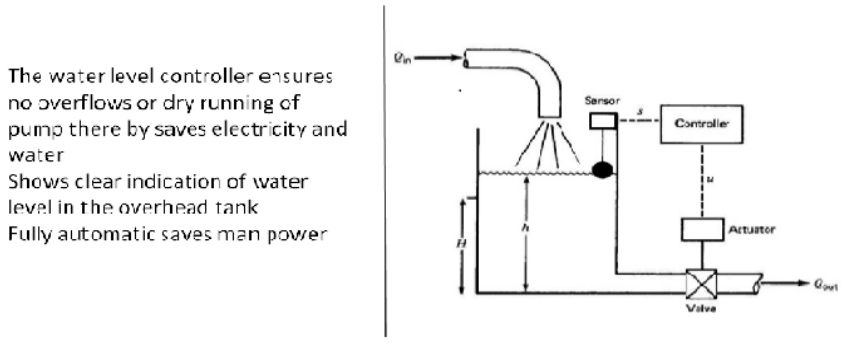

Fig. 1 PPT presented by a student magoring in Automation

After that, the students present the oral introduction of the automatic water control system during the class with about 5 minutes. This part is very important in training and testing their learning outcomes, their oral English and their ability of communication with others.

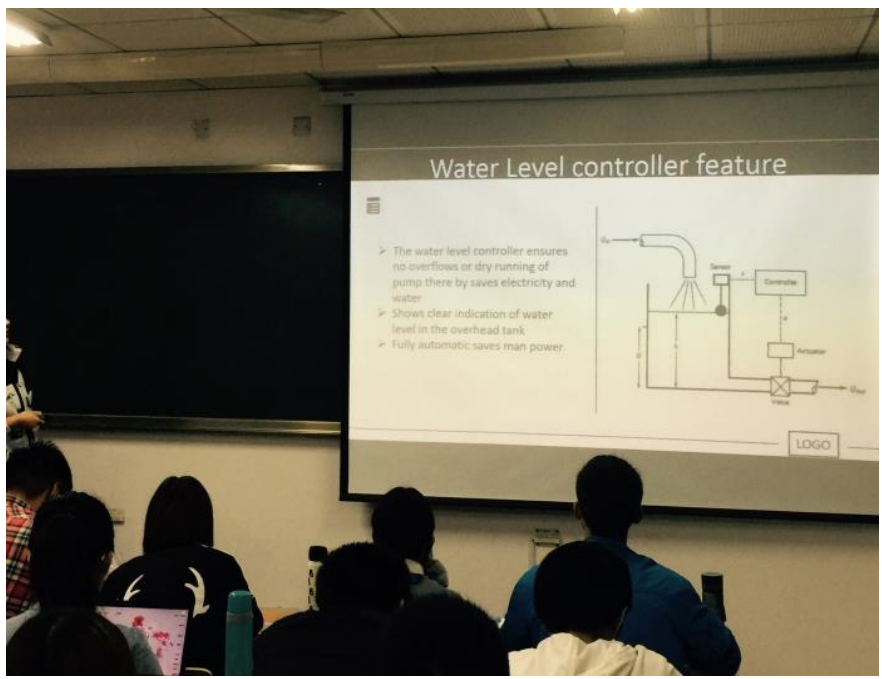

Fig. 2 Oral presentation by the student during the class 


\section{Reform of assessment method}

The prevailing assessment method is a combination of daily performance assessment and final examination, with a ratio of 3:7 [9-10]. Daily performance assessment includes attendance and homework. The final exam is aimed at checking students' learning outcomes by letting them take closed-book exams, and therefore neglects their effort and improvement. This study designs a new assessment method based on the reformation and construction of teaching contents, and aims to record students' performance at every stage of learning precisely, thus I can assess their comprehensive abilities and skills, and reflect the real process of their learning. Here are some specific assessment methods.

- Final exams, taking up a smaller amount of final grades, mainly aim at checking student's grasp of specialized English vocabulary, translation and writing skills. Closed-book examination items include (1) multiple choices and blanking filling, which test students' grasp of basic specialized English knowledge; (2) translation and writing, which check students' reading, translating and writing competence.

- In-class quiz, is not only an important part of teaching process, but an effective way to assess students' grasp of information and knowledge and to avoid students' cramming for final exams. Consequently, in-class quizzes, which contain multiple choice items, blank filling and translation of short sentences, should be attached more importance to, the aim of which is to check how much knowledge students have mastered.

- Homework is an indispensable part of assessment, which helps students practice what they have learned in class and grasp them more firmly. In addition to some translation work on the textbook, the teacher also asks students to search for online relative information about some equipment such as single chip, sensor, and PLC, etc., translate English instructions of chips, browse websites of some top universities and institutes to acquire information about this major, read more preference materials, and write about their experiences and feelings in learning.

- In order to develop students' abilities to acquire and analyze information, the teacher should encourage them to make full use of the rich academic resource database like IEEE or Springer offered by the university, retrieve and download papers or resources that they're interested in, and then make PPT files according to their own reading and understanding to introduce the background knowledge and contents of what they have read. In this way, students' abilities to retrieve literature, make PPT files and to think logically outweigh the contents of study.

- Students are arranged to present oral reports about what they have learned such as the frontier contents, technological application and practical prospects of this major, during which their expressive ability and confidence will be enhanced.
To sum up, the grade of this subject should appear as:

The final grade $=\mathrm{FS}(50 \%)+\operatorname{ICS}(15 \%)+\mathrm{HWS}(10 \%)+$ LPS $(15 \%)+(10 \%)$

Where FS is the score of final examination, ICS is the score of in-class quizzes, HW is the score of homework, LPS is the score of literature retrieval and PPT design, and SOR is the score of oral reports.

Apparently, the proposed assessment strategy is more comprehensive and more authentic than traditional assessment criterions. The in-class quiz can assess the students' ability of grasping knowledge. The projects presented independently by the students can assess the students' ability of information retrieval from online academic resources, and the oral presentation can assess the students' ability of oral English, the logical thinking and their psychological qualities.

\section{RESULTS OF THE STUDY}

From 2014 to 2016, this study has been carried out among automation majors of the three grades. As a compulsory course, the subject contained 32 periods within 16 weeks, during which there were 5 in-class quizzes. Students could customize teaching contents in their homework. They were also encouraged to make full use of university library to search for information and technical materials related to their major, for instance, driverless cars, unmanned aerial vehicle control, climbing robots, pattern recognition, and solar power generation, etc.

Aside from the 32 periods of class for each term, the teacher also arranged 6 periods to answer students' questions and organize discussions among students, during which students were encouraged to raise questions about what they didn't fully understand, and to present what they had searched for orally with the aid of multi-media courseware. In the process of oral reports, students' true abilities to retrieve and sort out information and to communicate with others have been reflected and their self-confidence has been raised. The teaching contents have been provided reasonably and accordantly to students' demand. The multi-media courseware that students have made was also made exquisitely and fruitfully.

During these three years, there were fewer students who skipped classes, and the atmosphere in class was much more lively than before, with students interacting with each other or the teacher more actively. They have all got satisfactory grades in final exams, together with the boost in their translating, writing, retrieving skills, their expressive ability and selfconfidence. The teacher also received marks higher than 90 in teaching assessment system and was warmly welcomed and accepted by students. Additionally, students have got a wider vision and could look up foreign literature for the topicselection and writing of thesis more willingly and actively. They could also write papers in English more smoothly with fewer mistakes and a more accurate grasp of specialized English vocabulary. 


\section{CONCLUSION}

This study carries out activities centered on students with the goal of fostering their abilities to acquire information and communicate with each other. Teaching contents have been redesigned based on students' needs and the assessment methods have been improved and varied. In-class group discussions have been organized from time to time, aside from which some other activities are held in class to evaluate students' daily performances, including in-class quizzes and oral presentations. Students can also raise questions after class to consult the teacher or discuss with each other. Teaching contents are chosen and customized by the students' needs, which raises their interest in learning and the interactive atmosphere in class. The practice indicates that this reformation in teaching can increase students' specialized English competence effectively, cultivate their abilities to read and consult, improve their expressive ability and self-confidence with satisfactory grades in exams, and help them make progress in writing abstracts in English in their theses.

\section{ACKNOWLEDGMENT}

The work is supported by Shandong Provincial Natural Science Foundation of China through the grant No. ZR201702200139.

\section{REFERENCES}

[1] T. Tanioka, "Improvement of students' basic ability for English majoring in electronic and electrical engineering through oral reading", IEEJ Transactions on Fundamentals and Materials, vol. 137, pp.516-521, 2017.

[2] M. Olga, "Engineering English: A lexical frequency instructional model", English for Specific Purposes, vol. 25, pp. 235-256, 2006.

[3] S. Subarna, "The incorporation of literature in the English language program for engineering students: learner interest and perception", 3L: Language, Linguistics, Literature, vol. 14, pp. 45-73,2008.

[4] X.Y.Cheng, "A novel probe into college English quality-oriented transformation based on the impersonal evaluation criteria of college English instruction", Theory and Practice in Language Studies. Theory and Practice in Language Studies, vol. 4, 736-742, 2014.

[5] Y.Yeh, H. C. Liou, and Y. H. Li, "Online synonym materials and concordancing for EFL college writing", Computer Assisted Language Learning, vol.20, pp.131-152, 2007.

[6] M A. Conroy, "Internet tools for language learning: university students taking control of their writing", Australas Journal of Education Technololy, vol. 26, pp.861-882, 2010.

[7] Y.Wu, X. H. Zhuang, and Q. Pan, "Modern college English education based on multimedia technology", Advanced Materials Research, pp.271-273, 2011

[8] F.Zhang, "Quality-improving strategies of college English teaching based on microlesson and flipped classroom", English Language Teaching, vol.10, pp. 243-249, 2017.

[9] Z. J. He, X. Yin, "The research on college English education evaluation system", International Conference on Economy, Management and Education Technology, pp.91-95, 2016.

[10] V. Klennowski, S. Askew, "Portfolio for learning assessment and professional development in higher education", Assessment and Evaluation in Higher Education, vol 3, pp. 267-286, 2006. 